\title{
Corneal Antigen-Presenting Cells: Diversity, Plasticity, and Disguise The Cogan Lecture
}

\section{Citation}

Dana, M. Reza. 2004. “Corneal Antigen-Presenting Cells: Diversity, Plasticity, and Disguise The Cogan Lecture." Investigative Opthalmology \& Visual Science 45 (3) (March 1): 722. doi:10.1167/ iovs.03-0803.

\section{Published Version}

10.1167/iovs.03-0803

\section{Permanent link}

http://nrs.harvard.edu/urn-3:HUL.InstRepos:34388131

\section{Terms of Use}

This article was downloaded from Harvard University's DASH repository, and is made available under the terms and conditions applicable to Other Posted Material, as set forth at http:// nrs.harvard.edu/urn-3:HUL.InstRepos:dash.current.terms-of-use\#LAA

\section{Share Your Story}

The Harvard community has made this article openly available.

Please share how this access benefits you. Submit a story.

\section{Accessibility}




\title{
Corneal Antigen-Presenting Cells: Diversity, Plasticity, and Disguise The Cogan Lecture
}

\author{
M. Reza Dana
}

$\mathrm{T}$ he study of antigen-presenting cells (APCs) is important for all immune-mediated disorders because these cells are not only the "sentinels" of the immune system for detection of foreign antigens, but they also play a critical role in tolerance induction to both self- and foreign antigens. ${ }^{1-4}$ In addition to their role in immune surveillance and induction of antigenspecific immune reactivity and tolerance, APCs can also serve an important role in innate immunity due to their capacity to respond acutely to inflammatory insults or "danger" signals in peripheral tissues. ${ }^{5-7}$

APCs can be divided into two functional groups: "professional" and "nonprofessional" APC. Professional APCs are thus called because they generally have a high constitutive expression of major histocompatibility complex (MHC) class II antigen, as well as costimulatory molecules, and hence are capable of efficient provision of both signals for T-cell priming. ${ }^{2,8}$ Examples of professional APCs include dendritic cells (DCs), macrophages, B cells, and epithelial Langerhans cells (LCs). ${ }^{9,10}$ In contrast to professional APCs, nonprofessional APCs have a low T-cell stimulatory capacity because their constitutive expression of MHC class II antigen and costimulatory molecules is low; however, under certain circumstances (as may occur in inflammation) these cells may also provide requisite signals for T-cell priming. Examples of nonprofessional APCs include vascular endothelial and certain mesenchymal cells. The most potent APCs in most tissues are DCs and LCs. Indeed, these cells are also known to serve as the professional APCs of the cornea and ocular surface. ${ }^{11-16}$ Their activation and recruitment to the cornea has been associated with loss of "immune privilege" in the anterior segment, ${ }^{17}$ exacerbation of herpetic $^{18,19}$ and Pseudomonas ${ }^{20}$ keratitis, and amplification of transplant immunity. ${ }^{15,21-24}$

The focus of our laboratory has been on studying the molecular factors that mobilize corneal APCs. Specifically, we have been interested in determining the (1) adhesion factors at the level of the limbal vascular endothelium that are required for leukocyte recruitment from the intravascular compartment into the tissue matrix, (2) chemotactic signals that are critical for recruiting limbal APCs into the cornea, (3) phenotypic and functional alterations to APCs associated with their maturation in the inflamed corneal microenvironment, (4) molecular factors that allow for mobilization and egress of mature APCs into lymphatics, and (5) critical costimulatory factors required for T-cell priming in lymphoid organs. Most of our studies to date

From the Laboratory of Immunology, Schepens Eye Research Institute and Massachusetts Eye and Ear Infirmary, Harvard Medical School, Boston, Massachusetts.

Disclosure: M.R. Dana, Allergan, Inc., Biogen, Inc. (C)

Corresponding author: Reza Dana, Laboratory of Immunology, Schepens Eye Research Institute and Massachusetts Eye and Ear Infirmary, Harvard Medical School, 20 Staniford St., Boston, MA; dana@vision.eri.harvard.edu. addressing the above questions have exploited the orthotopic corneal transplant model in the mouse. This model, while technically challenging, offers distinct advantages for the study of corneal immunobiology. First, to the extent that they have been studied, the cellular and molecular mechanisms of murine corneal allotransplant rejection largely resemble those of the human. Second, because of its clarity, the cornea is a perfect tissue for directly observing immunoinflammatory responses without the need to sacrifice the eye or the animal. Third, because of its easy accessibility, the cornea is an optimal tissue for atraumatic local immune modulation. Fourth, known immunogenetic differences between inbred strains of mice make this corneal model an optimal method for delineating the contribution of donor versus host-derived cells to the generation of the immune response to corneal antigens. Finally, and importantly, the study of corneal graft (by far the most common form of transplantation) immunology remains a priority because of the propensity of corneal grafts to be rejected when they are grafted onto inflamed host beds. ${ }^{25-27}$

\section{Recruitment of Limbal APCs into the Cornea}

It has been known for a long time that the limbus, the area between the vascularized conjunctiva and avascular cornea, has a significant resident population of MHC class $\mathrm{II}^{+} \mathrm{LCs}$, which when stimulated can be recruited into the cornea. ${ }^{15,21,28-33}$ What are the molecular factors that mediate the recruitment of these cells? It is well known that in general the migration of leukocytic populations to peripheral tissues requires the concerted activity of adhesion and chemotactic factors. ${ }^{34}$ Cell adhesion molecules (CAMs) regulate both cellcell and cell-matrix interactions. A classic example of the former is the interaction between leukocytes and vascular endothelial cells (VECs) that allow leukocytes to adhere and roll on the VECs before their transendothelial migration from the intravascular compartment into the tissue matrix. ${ }^{35-37}$ The transcriptional expression of many CAMs is under the regulation of signal-transduction pathways, such as NF- $\kappa \mathrm{B}$, that are in turn activated by proinflammatory cytokines and microbial products such as lipopolysaccharide (LPS). ${ }^{38}$

An early clue to the specific molecular mechanisms that initiate APC recruitment into the cornea was the identification of interleukin (IL)-1 as a principal proinflammatory cytokine that is secreted by the cornea itself at high levels within hours of inflammatory or immunogenic insult. ${ }^{32}$ The function of IL-1 requires ligation of IL- 1 receptor I by agonistic ligands IL-1 $\alpha$ and IL- $1 \beta$; conversely, the high-affinity binding of the receptor by IL-1 receptor antagonist (IL-1Ra) not only fails to generate signaling, but also competitively prevents binding of the receptor by the agonistic ligands. ${ }^{39,40}$ We have shown that the early expression of IL-1 by the inflamed cornea leads to profound upregulation in the expression of intercellular adhesion molecule (ICAM)-1 by the limbal vascular endothelium, which pre- 
cedes the recruitment of leukocytes to the peripheral cornea. ${ }^{41}$ The critical role of ICAM-1 in mediating the early leukocytic recruitment is underscored by our studies of ICAM-1 knockout animals and by the topical application of IL-1Ra (which leads to near-total downmodulation of ICAM-1 expression). In both settings, extravasation of innate immune cells (including macrophages and neutrophils) is dramatically suppressed. ${ }^{41,42}$ In the corneal transplantation model, the recruitment of limbal (i.e., host-derived) LCs into the allografts is likewise suppressed by $70 \%$ to $90 \%$ as a result of IL-1 blockade with IL-1Ra. ${ }^{43}$ However, because the peak recruitment of LC/DC elements into the cornea is preceded by infiltration of neutrophils (and to a lesser extent macrophages), our overall paradigm has emphasized the early role of these innate immune cells, in large part in response to ICAM-1 overexpression, as a critical facet of subsequent infiltrating waves of APCs into the cornea. ${ }^{44}$ In turn, the functional relevance of APC recruitment into the cornea prior to generation of any demonstrable T-cell-mediated immune reactivity is reflected in the profound effect that suppression of APC infiltration into the cornea has on allograft survival. For example, blockade of limbal LC infiltration into grafts effected by local IL-1 suppression is associated with a profound suppression of both allospecific delayed-type hypersensitivity (DTH) and frequency of allorejection. ${ }^{43,45}$

The role of IL-1 in mobilizing corneal APCs is far from absolute. Indeed, we have been impressed by the fact that local IL-1 suppression has a more limited effect on modulating generation of immunity in the setting of "high-risk" allografts (i.e., performed in presensitized hosts or those with inflamed recipient beds) compared with its immunomodulatory role in "lowrisk" grafts performed onto uninflamed host beds. ${ }^{45}$ Initial clues to the involvement of another proinflammatory cytokine, tumor necrosis factor (TNF)- $\alpha$, in mobilizing limbal LCs came when we determined that many limbal LCs do not express IL-1R and IL-1 has a very limited capacity in recruiting LCs in TNF-knockout hosts, whereas TNF- $\alpha$ can mediate LC recruitment into the cornea even in IL-1RI knockouts, ${ }^{46}$ thereby establishing TNF as a critical mediator of the induction phase of corneal immunity. ${ }^{44,47,48}$

Given that TNF- $\alpha$ is a highly pleiotropic cytokine, how does it mediate corneal immunity? Insight into this area came through our studies focusing on chemokine immunobiology in the context of corneal transplantation. ${ }^{27,49-51}$ Chemokines, or chemotactic cytokines, are low-molecular-weight cytokines that act as the "traffic cops" of the immune cells by providing directional information (through a gradient) to infiltrating cells in tissues. ${ }^{34}$ Most limbal LCs express CCR5, a receptor in the $\mathrm{CC}$ or $\beta$ group of chemokines, whose role in mediating recruitment of limbal LCs into the cornea is reflected by the fact that CCR5-knockout animals demonstrate a significant blunting in their capacity to mobilize LCs in response to corneal injury (Vora SR, et al. IOVS 2001;42:ARVO Abstract 2538). Similarly, we have shown that local suppression of TNF- $\alpha$ signaling (through the use of soluble TNFR) can significantly suppress limbal LC recruitment into the cornea by effective suppression of gene transcription for regulated on activation normal T-cell expressed and secreted (RANTES) and macrophage inflammatory protein (MIP)- $1 \beta,{ }^{48}$ two principal ligands of CCR5. ${ }^{52}$

In conclusion, IL- 1 and TNF- $\alpha$ can act in concert to recruit APCs from the limbus into the cornea by mediating the expression of cell adhesion factors (e.g., ICAM-1) and chemokines, in particular those that mediate signaling through the CCR5 receptor. Indeed, the maximally effective immunomodulatory strategy for blocking APC ingress into the cornea, as far as we know, is the combination of IL- 1 and TNF- $\alpha$ blockade (Vora SR, et al. IOVS 2001;42:ARVO Abstract 2538).

\section{Corneal APCs: A Heterogeneous Cast of Cells}

Until recently, it was thought that the normal cornea is essentially devoid of all bone-marrow-derived cellular, including APC, elements. ${ }^{15,16,28,30}$ Indeed, this putative unique feature of the cornea was maintained to be central to the immune privilege enjoyed by the cornea and ocular anterior segment. ${ }^{15,23,53}$ This tenet was refuted recently with the definitive demonstration that the cornea in fact possesses its own resident bonemarrow-derived $\mathrm{CD} 45^{+}$population. First, our laboratory identified CD $11 \mathrm{c}^{+} \mathrm{CD} 11 \mathrm{~b}^{-}$LCs in the epithelium (including central regions) of the normal cornea that bear classic ultrastructural features of epidermal LCs. ${ }^{11,13}$ Second, both our and Hendricks' laboratories have recently identified $\mathrm{CD} 45^{+} \mathrm{CD} 11 \mathrm{~b}^{+} \mathrm{CD} 11 \mathrm{c}^{-}$ monocytic cells in the corneal stroma. ${ }^{12,54}$ Third, in the very anterior portions of the corneal stroma, we have also identified a population of myeloid $\left(\mathrm{CD} 8 \alpha^{-}\right)$monocytic $\left(\mathrm{CD} 11 \mathrm{~b}^{+}\right)$ CD $11 \mathrm{c}^{+} \mathrm{DCs}^{12}$ that demonstrate a distinct ultrastructure compared with the monocytic CD11 ${ }^{-}$cells present in the more posterior portions of the cornea. Finally, a fourth population of $\mathrm{CD} 14^{+}$undifferentiated or precursor-type cells have been identified throughout the corneal stroma, most of which fail to express classic monocytic or DC surface markers. ${ }^{11,12}$

As discussed earlier, for APCs to prime T cells, they must present antigen in the groove of MHC class II, along with requisite costimulatory signaling. However, what is unique to the bone-marrow-derived cells of the central cornea is that they are universally both MHC class II- and costimulatoryfactor (CD40, CD80, CD86)-negative. ${ }^{12}$ Although highly immature APC populations have been identified in lymphoid organs and blood, ${ }^{2,55,56}$ no other tissue has been reported to be replete with universally $\mathrm{MHC}$ class II-negative $\mathrm{CD} 45^{+}$cells. It is the discordance between the cell surface expression of classic APC markers by these corneal cells and by similar lymphoreticular cells in other tissues that accounts for the "disguising" characteristic of the corneal bone-marrow-derived cells. Indeed, in retrospect, the failure to detect constitutively MHC class II-expressing resident cells in the corneas was the principal reason for the (inaccurate) conclusion that the cornea is devoid of resident lymphoreticular cells. ${ }^{30}$

\section{Functional Aspects of Corneal Bone-Marrow-Derived Cells}

Although the centrally located CD45+ cells of the cornea do not express the full complement of classic APC cell surface markers, approximately half of the $\mathrm{CD} 45^{+}$cells in the corneal periphery and limbus do. ${ }^{11,57}$ At least two important questions arise: Does the phenotype of the bone-marrow-derived cells (i.e., both those that normally reside in the cornea and those that are recruited there from the limbus) in the cornea change in inflammation? And, are these bone-marrow-derived cells actually capable of functionally serving as APCs for corneal antigens? As for the first question, our experimental data suggest that in addition to the recruitment of a large number of cells from the limbus into the cornea (through the molecular mechanisms detailed earlier), there is also a profound upregulation in the expression of MHC class II and costimulatory molecules (CD80/CD86) by resident corneal (as well as limbal) bone-marrow-derived cells in response to inflammation. ${ }^{11,13,57}$ These changes are experimentally very nicely reflected after corneal allotransplantation, because one can differentiate the limbal host-derived cells from the (donor) graftresiding $\mathrm{CD} 5^{+}$cells based on their expression of different MHC molecules. We have shown that, although the normal corneal graft tissue remains incapable of significant MHC class II expression as late as 12 hours after transplantation, by 24 
hours there is significant expression of donor-type MHC class II-in particular near the graft-host junction, which coincides with the area of most significant inflammation in transplantation. ${ }^{13,57}$ Hence, in the aggregate, at least from the standpoint of cell surface markers, corneal bone-marrow-derived cells can phenotypically mature into cells that express "classic" APC markers.

To demonstrate their functional capacity as APCs, we used transgenic green fluorescent protein (GFP) donor grafts transplanted into wild-type (non-GFP-expressing) hosts. Our data clearly show that graft-derived cells can be detected leaving the transplant and migrating centrifugally into the recipient rim, and eventually localizing into the ipsilateral draining lymph nodes of the host-strongly suggesting that these cornea-derived cells can act as "passenger leukocytes" in the context of transplantation immunology. ${ }^{14}$ Initial clues as to the functional relevance of this traffic came when we demonstrated that disruption of the eye-lymph node axis, through surgical cervical lymphadenectomy, leads to both complete abrogation of host allosensitization and universal and indefinite allograft survival. $^{58,59}$ Indeed, these data demonstrate that the functional presence of the eye-lymph node axis (immunization) can be directly juxtaposed with the oculosplenic axis (tolerance induction). ${ }^{58,59}$

From a conceptual standpoint, however, both host and donor-derived APCs should be able to gain access to the draining lymph node; hence, the lymphadenectomy data referenced earlier did not definitely relate the induction of immunity in lymph nodes to the donor (graft-derived) APCs, per se. It is important at this juncture to review briefly and distinguish "direct" from "indirect" allosensitization in transplantation, as these concepts have a considerable impact on our discussion. In direct sensitization, graft-borne passenger leukocytes serve as APCs by directly presenting alloantigen(s) in the context of donor-type MHC class II to naïve host T cells. ${ }^{60}$ In contrast, in indirect sensitization, host-derived (i.e., limbal) APCs infiltrate the graft, and pick up and process alloantigens that they present in the context of host-type MHC class II to self-restricted $\mathrm{T}$ cells. ${ }^{61}$ Because the cornea was always said to be devoid of bone-marrow-derived MHC class $\mathrm{II}^{+}$cells, the role of the direct pathway has been thought to be either nonexistent or inconsequential. ${ }^{31,44}$

Hence, in the context of these different pathways to allosensitization, the central question as to the functionality of the cornea (or graft)-borne cells remained whether they were capable of direct priming of host $\mathrm{T}$ cells. To answer this question, we used the highly sensitive ELISPOT method to assay for the frequency of host T-cells primed directly by donor APCs. Lymph node cells were harvested after transplantation, and the T-cells were column-purified before coincubation with donor APC stimulators. Capture monoclonal antibodies were then used to determine the frequency of the direct T-cell response. Our data clearly demonstrate that in high-risk corneal transplantation (grafting onto inflamed recipient beds), but not in low-risk grafting (grafting onto normal and uninflamed host beds), there is significant induction of IL-2- and IFN- $\gamma$-secreting, directly primed $\mathrm{CD}^{+}{ }^{+} \mathrm{T}$ cells well before the onset of clinical rejection (Huq S, et al. IOVS 2002;43:ARVO E-Abstract 2275). Are these directly primed T cells relevant in terms of corneal graft rejection? The answer is a resounding yes: Indeed, MHC class II- knockout donor corneas (by definition incapable of priming a host $\mathrm{CD}^{+} \mathrm{T}$ cell response) when grafted onto high-risk host beds are rejected at a significantly lower frequency and rapidity than are wild-type donor corneas. Importantly, even when the direct pathway is blocked by using class II-knockout donors, the frequency of rejection is still higher than that normally occurring in low-risk transplantation, suggesting that the indirect pathway continues to play a dis- tinct, though not exclusive, role in host sensitization in highrisk transplantation (Huq, et al. IOVS 2003;44:ARVO E-Abstract 3211).

Taken together, two fundamental conclusions can be drawn from these results. First, these data are the first to illustrate definitively the direct contribution of cornea-derived cells in generating the immune response to corneal (in this case allo-) antigens. Second, these data illustrate, to our knowledge for the first time, how the microenvironmental specificities of the transplantation site (e.g., the degree of inflammation or vascularity) can have a profound effect on the differential contribution of the distinct pathways of sensitization generated in the host in response to grafted antigens. An important corollary of this finding is that the strategies used to modulate immunity to allografts (i.e., directed at host-versus-donor factors) may have to be fundamentally different, depending on the type of graft (high-risk versus low-risk) performed.

\section{Molecular Regulation of Corneal APC Trafficking to Lymph NoDes}

The data summarized herein suggest that corneal bone-marrow-derived cells are capable of trafficking relatively efficiently to lymphoid organs and functioning as APCs for priming $T$ cells. Indeed, the rapidity of this trafficking and expression of MHC antigens by these cells clearly debunks the myth that antigenic sequestration is the principal barrier to immune reactivity to corneal antigens. But how do these cells so readily gain access to lymphoid reservoirs? And how is this trafficking possible, particularly since the cornea is not only avascular, but more importantly (from the standpoint of APC trafficking), also without lymphatics? There are two explanations: one microanatomical and the other functional. First, although the cornea is lymphatic-free, lymphatic vessels can readily grow into it on inflammatory stimulation ${ }^{62,63}$; moreover, the conjunctiva is lymphatic rich and so corneal APCs may, at least theoretically, readily gain access to these lymphatics on (centrifugal) migration beyond the limbus. Second, we have recently determined that the same molecular mechanisms that regulate corneal lymphangiogenesis also mediate APC trafficking into afferent lymphatics. How is this possible? The answer to this lies with signaling mediated by vascular endothelial growth factor receptor (VEGFR)-3, a receptor that is distinct from VEGFR-1 (flt-1) and VEGFR-2 (flt-2) that regulate blood angiogenesis. ${ }^{64,65}$ The ligands to VEGFR-3 are VEGF-c and VEGF-d, both of which can serve as growth factors for lymphatic endothelium ${ }^{66-68}$ and hence can result in lymphangiogenesis. We have recently discovered that VEGFR-3 overexpression by endothelial cells in response to inflammation is also accompanied by surface expression of VEGFR-3 by mature (but not immature) corneal DCs. ${ }^{69}$ Indeed, we have shown that in corneal inflammation, the DCs and monocytes that congregate around the budding lymphatics are nearly all VEGFR- $3^{+}$, suggesting that they may respond to the same signals (e.g., VEGF-c) that induce lymphatic growth into the cornea. $^{70}$ The selective expression of VEGFR-3 by corneal $\mathrm{CD}_{11 \mathrm{c}^{+}}$DCs, but not by stromal keratocytes, has recently been confirmed by flow cytometry (Chen L, et al. IOVS. 2003; 44:ARVO E-Abstract 701). ${ }^{69}$

To confirm that the expression of VEGFR-3 by corneal DCs is indeed functional, we have recently performed transwell chemotactic assays with corneal DCs (cultured from corneal explants) and have shown a dose-dependent chemotactic response to VEGF-c. This chemotaxis could be blocked by a VEGFR-3/Ig chimeric molecule that suppresses VEGFR-3-mediated signaling (Chen, et al. IOVS 2003;44:ARVO E-Abstract 701). To demonstrate conclusively the in vivo relevance of 
these findings, we have quantified the trafficking of graftderived APCs after transplantation to ipsilateral lymph nodes, either after subconjunctival injection of VEGFR-3/Ig or a control Fc/Ig. We have shown that by blocking local VEGFR-3 signaling, we can profoundly suppress the migration of corneal APCs to regional draining lymph nodes. Does blockade of this pathway and APC trafficking have any demonstrable effect on the host immune response to corneal grafts? The answer is a resounding yes. Indeed, blockade of VEGFR-3 after corneal transplantation diminishes APC trafficking to the draining lymph nodes to a point where induction of allospecific DTH is significantly diminished. Because allograft rejection is mediated by DTH-effecting (T helper-1) T cells, the suppression of allospecific DTH through VEGFR-3 blockade also leads to a significant reduction in the rate of graft rejection (Chen, et al. IOVS 2003;44:ARVO E-Abstract 701). As described earlier, we showed several years ago that through surgical lymphadenectomy of draining regional lymph nodes in cornea graft hosts, we could engender universal and indefinite graft survival without the concomitant use of any local or systemic immunomodulatory agent. ${ }^{58}$ Accordingly, we have coined the term "molecular lymphadenectomy" to connote the functional effect of VEGFR-3 antagonism as a nonsurgical strategy that targets lymphatic drainage.

\section{T-Cell Priming: The Common Denominator of Adaptive ImMunity}

So far, we have focused almost exclusively on the trafficking of APCs from the intravascular compartment to the corneal tissue matrix and from the cornea to lymphoid organs by gaining access to afferent lymphatics through VEGFR-3 signaling. However, it is critical to emphasize that the functional relevance of this traffic is to bring the antigen-bearing APCs in intimate contact with a large number of naive $\mathrm{T}$ cells in lymphoid reservoirs (such as the lymph node) for priming of antigenspecific immunity. By dissecting the molecular mechanisms involved in this trafficking, we have identified multiple steps that can be targeted, with resultant suppression of immune responsiveness.

The fact that the common denominator in generating an adaptive immune response is the priming of T cells, rather than any one of the steps related to APC trafficking as we have outlined, has been confirmed by our studies focusing on blocking the interaction of CD40 with CD40 ligand (CD40L; also known as CD154). CD40 is a critical costimulatory molecule expressed by many APCs (including corneal DCs and LCs), whose ligation by CD154 leads to overexpression of CD80 (B7.1), CD86 (B7.2), and IL-12- critical factors in priming a T helper-1 response. ${ }^{71}$ We have provided conclusive evidence that administration of anti-CD154 can block both the direct and indirect pathways of allosensitization, thereby promoting immunologic "ignorance" (based on failure to induce T-cell priming) but without promoting active tolerance or significant $\mathrm{T}$ helper-2 skewing. ${ }^{51,72,73}$ Indeed, in corneal transplant hosts treated with anti-CD154, DTH fails to develop in response to corneal antigens, and they demonstrate near-universal acceptance of corneal allografts, even in the high-risk setting, as long as the systemic treatment is sustained.

It is important to emphasize that the mechanisms we have focused on, namely those that regulate APC infiltration into the cornea and their mobilization to lymphatics, and finally priming of naïve $T$ cells, all comprise the sensitization (or afferent) arm of the alloimmune response (Fig. 1) in contrast to the effector (or efferent) mechanisms that mediate the $\mathrm{T}$ cell targeting of the graft. Indeed, once primed, alloreactive effector $\mathrm{T}$ cells must undergo clonal expansion, peripheralize, and target

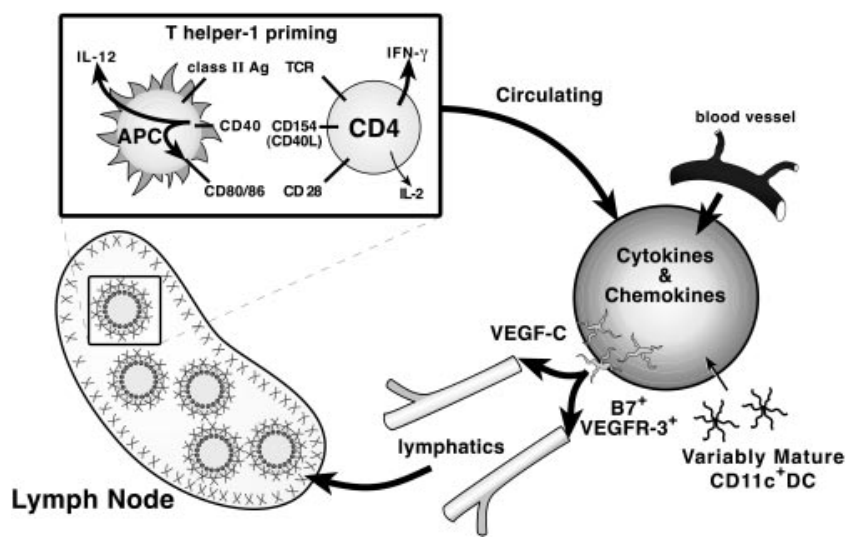

FiguRE 1. Graphic representation of the mechanisms involved in induction of immunity by corneal APCs. Corneal expression of proinflammatory cytokines (e.g., IL-1 and TNF- $\alpha$ ) and chemokines in response to antigenic challenge (or other "danger signals") leads to recruitment of innate immune cells, followed rapidly by influx of $\mathrm{CD}_{11 \mathrm{c}^{+}}{ }^{\mathrm{DC} / \mathrm{LC}}$ elements from the limbus into the cornea. Expression of ICAM-1 by the VECs plays a critical role in initiating this process. These cells, along with the heterogeneous bone marrow elements that are normally resident in the cornea, express VEGFR-3 in response to inflammation-a process that coincides temporally with these cells' acquisition of maturation markers, including MHC class II and B7 (CD80, CD86) costimulatory molecules. In response to VEGF-c, the VEGFR- $3^{+}$cells are recruited to afferent lymphatics that serve as conduit for these APCs to gain access to high concentrations of naive $T$ cells present in the parafollicular areas of the lymph nodes. Ligation of CD40 on APCs by CD154 (CD40L) expressed by CD4 T cells leads to release of IL-12 and induction of a T helper-1 response to corneal antigens presented by the APCs.

the graft before any demonstrable clinical rejection. Our preliminary data suggest that these effector processes are mediated by wholly different chemokine systems (mediated by CCR1 and CXCR3) than those that mediate the ingress of immature APCs into the cornea, as we described earlier in the lecture. ${ }^{74}$ Finally, we want to emphasize that, as elaborate and redundant as the mechanisms that regulate immunity are, the data described herein clearly demonstrate that blockade of even one molecular pathway (e.g., CD154 or VEGFR-3) can have profound effects on immunity through regulating highly disparate mechanisms (suppression of costimulation versus APC trafficking).

\section{Implications AND CONCLUDING REMARKS}

In conclusion, we have demonstrated that the normal cornea in fact possesses a heterogeneous population of resident bonemarrow-derived cells, including DCs. These cells have the unique feature of being universally immature or of a precursor phenotype and hence have the "disguising" feature of being ubiquitously MHC class II-negative, and many of these cells, including the DCs, have the functional plasticity of migrating out of the cornea, overexpressing requisite costimulatory molecules, presenting antigen, and stimulating $\mathrm{T}$ cells under inflammatory conditions. Moreover, we have shown how the processes that mediate the ingress of these APC populations into the cornea during inflammation are distinct from those that mediate the egress of these cells into lymphatics, demonstrating how the modulation of each of these steps can affect induction of immunity to corneal antigens.

Many critical issues remain unresolved. For example, it is thought that resident APCs in the periphery are recruited from the intravascular compartment. Given that the bone marrow elements we have identified in the cornea are universally MHC 
class II-negative, whereas only a small population of similar cells in the blood are in such a premature state, there are two relevant questions: Where do the corneal cells come from, and what microenvironmental factors suppress the maturity state of these leukocytes as they gain entry into the normal cornea? Finally, whereas we have focused on the role of these resident bone marrow elements in inducing immune responsiveness, it is critical to determine what role, if any, these cells may have in the induction of tolerance.

Although we expect that ongoing investigations will eventually provide insights into the answers to these questions, it is also important to emphasize the general implications of these findings in terms of our understanding of corneal physiology and immunopathology. Whether it has been generation of immunity to transplants or innate immune responses to infection or injury, the cornea has historically been seen as a simple collagenous tissue at the mercy of the host immune system. The novel findings described herein may lead to a paradigm shift in our understanding of corneal immunity as we move away from the concept of the cornea as a passive bystander, to a model that incorporates its role as an active participant in orchestrating the immune system in response to foreign or autoantigens.

\section{Acknowledgments}

I am greatly indebted to the many trainees who have worked in my laboratory. It is through their commitment to our shared scientific and educational goals and their tenacity and ingeniousness that we are able to make new discoveries. Specifically, I thank the following individuals (listed alphabetically) for their contribution to the work I have presented in the Cogan Lecture: In the area of cytokines and chemokines, Clay Beauregard, Iva Dekaris, Sudhir Vora, Jun Yamada, Satoru Yamagami, and Suning Zhu; in the area of APC phenotyping and function, Lu Chen, Pedram Hamrah, Syed Huq, Ying Liu, and Qiang Zhang; in the area of costimulation, Ying Qian and Vikas Tewari; and in the area of ocular surface inflammation, Mini Balaram and Abha Sood-Gulati. I extend special thanks to Jackie Doherty for assisting in the management of our laboratory research team and to Pedram Hamrah for assistance in the preparation of the manuscript. In addition, I acknowledge the contribution of several key colleagues and collaborators in our research (listed alphabetically): Gilles Benichou, Ilene Gipson, Andrius Kazlauskas, Bruce Ksander, Wayne Streilein, David Sullivan, and Andrew Taylor. I also thank the following sources who have been instrumental in allowing us to pursue our research goals: The National Eye Institute, the Eye Bank Association of America, Research to Prevent Blindness, Fight-For-Sight, the U.S. Department of Defense, Massachusetts Lions Eye Research Fund, and the corporations Allergan, Amgen, and Biogen. I have been fortunate to have benefited immensely from the guidance provided me by my teachers and mentors throughout my education and career. It is not possible to list all the individuals who have helped me through the years, but, in particular, I would like to acknowledge my colleague and mentor, J. Wayne Streilein, MD, for his guidance, support, and encouragement through the years.

\section{References}

1. Banchereau J, Steinman RM. Dendritic cells and the control of immunity. Nature. 1998;392:245-252.

2. Banchereau J, Briere F, Caux C, et al. Immunobiology of dendritic cells. Annu Rev Immunol. 2000;18:767-811.

3. Thomson AW, Lu L, Murase N, Demetris AJ, Rao AS, Starzl TE. Michrochimerism, dendritic cell progenitors and transplantation tolerance. Stem Cells. 1995;13:622-639.

4. Thomson AW, Lu L. Dendritic cells as regulators of immune reactivity: implications for transplantation. Transplantation. 1999;68:1-8.
5. Rescigno $M$, Borrow $P$. The host-pathogen interaction: new themes from dendritic cell biology. Cell. 2001;106:267-270.

6. Kelsall BL, Biron CA, Sharma O, Kaye PM. Dendritic cells at the host-pathogen interface. Nat Immunol. 2002;3:699-702.

7. Palucka K, Banchereau J. How dendritic cells and microbes interact to elicit or subvert protective immune responses. Curr $O p$ Immunol. 2002;14:420-431.

8. Mellman I, Steinman RM. Dendritic cells: specialized and regulated antigen processing machines. Cell. 2001;106:255-258.

9. Steinman RM. The dendritic cell system and its role in immunogenicity. Annu Rev Immunol. 1991;9:271-296.

10. Liu Y-J. Dendritic cell subsets and lineages, and their functions in innate and adaptive immunity. Cell. 2001;106:259-262.

11. Hamrah P, Huq SO, Liu Y, Zhang Q, Dana MR. Corneal immunity is mediated by heterogeneous population of antigen-presenting cells. J Leukoc Biol. 2003;4:172-176.

12. Hamrah P, Liu Y, Zhang Q, Dana MR. The corneal stroma is endowed with significant numbers of resident dendritic cells. Invest Ophthalmol Vis Sci. 2003;44:581-589.

13. Hamrah P, Zhang Q, Liu Y, Dana MR. Novel characterization of MHC class II-negative population of resident corneal Langerhans cell-type dendritic cells. Invest Ophthalmol Vis Sci. 2002;43:639646.

14. Liu Y, Hamrah P, Zhang Q, Taylor AW, Dana MR. Draining lymph nodes of corneal transplant hosts exhibit evidence for donor major histocompatibility complex (MHC) class II-positive dendritic cells derived from MHC class II-negative grafts. J Exp Med. 2002;195: 259-268.

15. Niederkorn JY. The immune privilege of corneal allografts. Transplantation. 1999;67:1503-1508.

16. Jager MJ. Corneal Langerhans cells and ocular immunology. Reg Immunol. 1992;4:186-195.

17. Dana MR, Streilein JW. Loss and restoration of immune privilege in eyes with corneal neovascularization. Invest Ophthalmol Vis Sci. 1996;37:2485-2494.

18. Jager MJ, Atherton SS, Bradley D, Streilein JW. Herpetic stromal keratitis in mice: less reversibility in the presence of Langerhans cells in the central cornea. Curr Eye Res. 1991;10:69-73.

19. McLeish W, Rubsamen P, Atherton SS, et al. Immunobiology of Langerhans cells on the ocular surface. II. Role of central corneal Langerhans cells in stromal keratitis following experimental HSV-1 infection in mice. Reg Immunol. 1989;2:236-243.

20. Hazlett LD. Pathogenic mechanisms of P. aeruginosa keratitis: a review of the role of T cells, Langerhans cells, PMN, and cytokines. DNA Cell Biol. 2002;21:383-390.

21. Williamson JSP, Dimarco S, Streilein JW. Immunobiology of Langerhans cells on the ocular surface. I. Langerhans cells within the central cornea interfere with induction of anterior chamber associated immune deviation. Invest Opbthalmol Vis Sci. 1987;21: $759-765$.

22. Streilein JW. What do T lymphocytes "see" when penetrating keratoplasty fails? Cornea. 2000;19(suppl 3):S146-S154.

23. Streilein JW. Immunobiology and immunopathology of corneal transplantation. Chem Immunol. 1999;73:186-206.

24. Niederkorn JY, Peeler JS, Ross J, Callanan D. The immunogenic privilege of corneal allografts. Reg Immunol. 1989;2:117-124.

25. Mader TH, Stulting RD. The high-risk penetrating keratoplasty. Opbthalmol Clin North Am. 1991;4:411-426.

26. Foulks GN, Sanfilippo F. Beneficial effects of histocompatibility in high-risk corneal transplantation. Am J Opbthalmol. 1982;94:622629.

27. Hamrah P, Djalilian AR, Stulting RD. Immunologic high-risk penetrating keratoplasty. In: Krachmer JH, Mannis MJ, Holland EJ, eds. Cornea. St. Louis: Mosby. In press.

28. Gillette TE, Chandler JW, Greiner JV. Langerhans cells of the ocular surface. Opbthalmology. 1982;89:700-711.

29. Jager MJ, Bradley D, Atherton SS, Streilein JW. Presence of Langerhans cells in the central cornea linked to the development of ocular herpes in mice. Exp Eye Res. 1992;54:835-841.

30. Streilein JW, Toews GB, Bergstresser PR. Corneal allografts fail to express Ia antigens. Nature. 1979;282:320-321. 
31. Sano Y, Ksander BR, Streilein JW. Fate of orthotopic corneal allografts in eyes that cannot support anterior chamber-associated immune deviation induction. Invest Opbthalmol Vis Sci. 1995;36: 2176-2185.

32. Niederkorn JY, Peeler JS, Mellon J. Phagocytosis of particulate antigens by corneal epithelial cells stimulates interleukin-1 secretion and migration of Langerhans cells into central cornea. Reg Immunol. 1989;2:83-90.

33. Hazlett LD, McClellan SM, Hume EB, Dajcs JJ, O'Callaghan RJ, Willcox MD. Extended wear contact lens wear usage induces Langerhans cell migration into cornea. Exp Eye Res. 1999;69:575577.

34. Luster AD. Chemokines-chemotactic cytokines that mediate inflammation. $N$ Engl J Med. 1998;338:436-445.

35. Tedder TF, Steeber DA, Chen A, Engel P. The selectins: vascular adhesion molecules. FASEB J. 1995;9:866-873.

36. Alon R, Feigelson S. From rolling to arrest on blood vessels leukocyte tap dancing on endothelial integrin ligands and chemokines at sub-second contacts. Semin Immunol. 2002;14:93-104.

37. Dunon D, Piali L, Imhof BA. To stick or not to stick: the new leukocyte homing paradigm. Curr Opin Cell Biol. 1996;8:714723 .

38. Collins T, Read MA, Neish AS, Whitley MZ, Thanos D, Maniatis T. Transcriptional regulation of endothelial cell adhesion molecules: NF-kappa B and cytokine-inducible enhancers. FASEB J. 1995;9: 899-909.

39. Hannum $\mathrm{CH}$, Wilcox $\mathrm{CJ}$, Arend WP, et al. Interleukin-1 receptor antagonist activity of a human interleukin-1 inhibitor. Nature. 1990;343:336-340.

40. Eisenberg SP, Evans RJ, Arend WP, et al. Primary structure and functional expression from complementary DNA of a human interleukin-1 receptor antagonist. Nature. 1990;343:341-346

41. Zhu SN, Dana MR. Expression of cell adhesion molecules on limbal and neovascular endothelium in corneal inflammatory neovascularization. Invest Opbthalmol Vis Sci. 1999;40:1427-1434.

42. Zhu SN, Yamada J, Streilein JW, Dana MR. ICAM-1 deficiency suppresses host allosensitization and rejection of MHC-disparate corneal transplants. Transplantation. 2000;69:1008-1013.

43. Yamada J, Dana MR, Zhu SN, Alard P, Streilein JW. Interleukin 1 receptor antagonist suppresses allosensitization in corneal transplantation. Arch Opbthalmol. 1998;116:1351-1357.

44. Dana MR, Qian Y, Hamrah P. Twenty-five-year panorama of corneal immunology: emerging concepts in the immunopathogenesis of microbial keratitis, peripheral ulcerative keratitis, and corneal transplant rejection. Cornea. 2000;19:625-643.

45. Dana MR, Yamada J, Streilein JW. Topical interleukin 1 receptor antagonist promotes corneal transplant survival. Transplantation 1997;63:1501-1507.

46. Dekaris I, Yamada J, Streilein JW, Dana MR. Effect of topical interleukin-1 receptor antagonist (IL-1 ra) on corneal allograft transplant survival in presensitized hosts. Curr Eye Res. 1999;19:456459.

47. Dekaris I, Zhu SN, Dana MR. TNF- $\alpha$ regulates corneal Langerhans cell migration. J Immunol. 1999;162:4235- 4239.

48. Qian Y, Dekaris I, Yamagami S, Dana MR. Topical soluble tumor necrosis factor receptor type I suppresses ocular chemokine gene expression and rejection of allogeneic corneal transplants. Arch Ophthalmol. 2000;118:1666-1671.

49. Yamagami S, Miyazaki D, Ono S, Dana MR. Differential chemokine gene expression after corneal transplantation. Invest Ophthalmol Vis Sci. 1999;40:2892-2897.

50. Hamrah P, Liu Y, Yamagami S, Zhang Q, Vora S, Dana MR. Targeting the chemokine receptor CCR1 suppresses corneal alloimmunity and promotes allograft survival. Clin Immunol. 2001;99:S118.

51. Hamrah P, Yamagami S, Liu Y, Zhang Q, Dana MR. Differential role of chemokines in corneal alloimmunity. Keystone Symposia: Chemokines and Chemokine Receptors. Taos, NM; 2001.
52. Qian Y, Hamrah P, Boisgérault F, et al. Mechanisms of immunotherapeutic intervention by anti-CD154 (CD40L) antibody in highrisk corneal transplantation. I Interferon Cytokine Res. 2003;22: 1217-1225.

53. Zlotnik A, Morales J, Hedrick JA. Recent advances in chemokines and chemokine receptors. Crit Rev Immunol. 1999;19:1-47.

54. Streilein JW. Immunologic privilege of the eye. Springer Semin Immunopatbol. 1999;21:95-111.

55. Brissette-Storkus CS, Reynolds SM, Lepisto AJ, Hendricks RL. Identification of a novel macrophage population in the normal mouse corneal stroma. Invest Ophthalmol Vis Sci. 2002;43:2264-2271.

56. Inaba K, Steinman RM, Witmer Pack M, et al. Identification of proliferating dendritic cell precursors in mouse blood. J Exp Med. 1992; 175:1157-1167.

57. Austyn JM, Hankins DF, Larsen CP, Morris PJ, Rao AS, Roake JA. Isolation and characterization of dendritic cells from mouse heart and kidney. J Immunol. 1994;152:2401-2410.

58. Hamrah P, Liu Y, Zhang Q, Dana MR. Alterations in corneal stromal dendritic cell phenotype and distribution in inflammation. Arch Opbthalmol. 2003;121:1132-1140.

59. Yamagami S, Dana MR. The critical role of draining lymph nodes in corneal allosensitization. Invest Ophthalmol Vis Sci. 2001;42: 1293-1298.

60. Yamagami S, Dana MR, Tsuru T. Draining lymph nodes play an essential role in alloimmunity generated in response to high-risk corneal transplantation. Cornea. 2002;21:405-409.

61. Lafferty KJ, Prowse SJ, Simeonovic CJ, Warren HS. Immunobiology of tissue transplantation: a return to the passenger leukocyte concept. Annu Rev Immunol. 1983;1:143-173.

62. Boisgérault F, Liu Y, Anosova N, Ehrlich E, Dana MR, Benichou G. Role of $\mathrm{CD}^{+}$and $\mathrm{CD}^{+} \mathrm{T}$ cells in allorecognition: lessons from corneal transplantation. J Immunol. 2001;167:1891-1899.

63. Collin HB. Lymphatic drainage of ${ }^{131}$ I-albumin from the vascularized cornea. Invest Ophthalmol Vis Sci. 1970;9:146-155.

64. Collin HB. Corneal lymphatics in alloxan vascularized rabbit eyes. Invest Ophthalmol Vis Sci. 1966;5:1-13.

65. Jussila L, Alitalo K. Vascular growth factors and lymphangiogenesis. Physiol Rev. 2002;82:673-700.

66. Veikkola T, Alitalo K. VEGFs, receptors and angiogenesis. Semin Cancer Biol. 1999;9:211-220.

67. Joukov V, Pajusola K, Kaipainen A, et al. A novel vascular endothelial growth factor, VEGF-C, is a ligand for the FLT4 (VEGFR-3) and KDR (VEGFR-2) receptor tyrosine kinases. EMBO J. 1996;15: $290-298$.

68. Achen MG, Jeltsch M, Kukk E, et al. Vascular endothelial growth factor D (VEGF-D) is a ligand for the tyrosine kinases VEGF receptor 2 (Flk1) and VEGF receptor 3 (FLT4). Proc Natl Acad Sci USA. 1998;95:548-553.

69. Kukk E, Lymboussaki A, Taira S, et al. VEGF-C receptor binding and pattern of expression with VEGFR-3 suggests a role in lymphatic vascular development. Development. 1996;122:3829-3837.

70. Hamrah P, Chen L, Zhang Q, Dana MR. Novel expression of vascular endothelial growth factor receptor (VEGFR)-3 and VEGF-C on dendritic cells in the cornea. Am J Pathol. 2003;163: 57-68.

71. Hamrah P, Zhang Q, Dana MR. Expression of vascular endothelial growth factor receptor-3 (VEGFR-3) in the conjunctiva: a potential link between lymphangiogenesis and leukocyte trafficking on the ocular surface. Adv Exp Med Biol. 2002;506:851-858.

72. Grewal IS, Flavell RA. The role of CD 40 ligand in costimulation and T cell activation. Immunol Rev. 1996;153:85-106.

73. Qian Y, Dana MR. Blockade of CD40-CD154 ligand costimulatory pathway promotes survival of allogeneic corneal transplants. Invest Ophthalmol Vis Sci. 2001;42:987-994.

74. Qian Y, Dana MR. Effect of locally administered anti-CD154 (CD40 ligand) monoclonal antibody on survival of allogeneic corneal transplants. Cornea. 2002;21:592-597. 